\title{
AC 2012-3470: ANALYSIS AND DEVELOPMENT OF A MODEL FOR THE CAUSES OF COST AND TIME OVERRUNS IN ENGINEERING PROJECTS
}

Dr. Syed Athar Masood, National University of Sciences \& Technology, Rawalpindi, Pakistan

Syed Athar Masood is working as Assistant Professor at the Department of Engineering, NUST College of E\&ME, Rawalpindi, Pakistan. He did his doctorate at Loughborough University, U.K., in engineering management at Wolfson School of Mechanical and Manufacturing Engineering and published a number of research papers in international journals. 


\title{
ANALYSIS AND DE VELOPMENT OF A MODEL FOR THE CAUSE S OF COST AND TIME OVERR UNS IN ENG INEERING PROJ ECTS
}

\begin{abstract}
Cost and time overruns have been the most disgusting problems in most engineering projects. There are number of factors such as funds unavailability at the proper time, unavailability of skilled manpower, incapability of management to manage project properly, lack of commitment from project team and problems in the of supply of raw material on time. By understanding the causes of cost and time overruns, we can control cost and time overruns in engineering projects. These overruns may be due to external or internal factors that make engineering projects to delay and over budget.

The main objective of this research is to explore the causes of overruns in engineering projects and to develop a model to overcome these causes. Literature review, personal visits to various engineering projects and data have been collected to explore the causes of overruns in the delayed engineering projects and to determine the types of delays causing overruns in terms of time and cost. Results indicate that most important factor to complete engineering projects on time and avoid budget overruns is the commitment and loyalty of the project team especially the top management. The commitment in true spirit of the project team and the management can be enhanced through clan type organizational culture in the project team as depicted by Cameron, $\mathrm{K}$. S. and Quinn'. The data of this research was analyzed using SPSS and a model was developed to overcome the causes of overrun in engineering projects.
\end{abstract}

\section{Introduction}

The completion of engineering projects without overruns is probably the most important current problem area for cost engineers and project managers ${ }^{2}$. Cost and time overruns have been the most disgusting problems in most engineering projects. Delays and cost overruns in major engineering projects have raised the capital-output ratio and have lowered the efficacy of project completion on both ends i.e., cost and schedule. Sydney Opera House, the Channel Tunnel and some of the Olympic Games are the most current well-known examples of cost and time overruns.

A study by Morris ${ }^{2}$ indicated rough estimates of delays and cost overruns, and the opportunity cost in terms of extra 'capital $x$ time' that was used up. Cost overruns (at $80 \%$ ) and the extra 'capital X time' incurred (about 190\%) are very large; even after removing the increase due to inflation. Factors internal to the public sector system and government largely account for the delays and cost overruns, e.g., poor project design and implementation, inadequate funding of projects, bureaucratic indecision, and the lack of coordination between enterprises. Appraisal by the government very often is devoid of meaning when the emphasis is only on the form of the project proposal rather 
than on its content - a tendency quite usual in bureaucracies. Some economists have argued that high cost production of capital and intermediate goods have led to high incremental capital-output ratios, which have tended to reduce the efficacy of investment in bringing about growth ${ }^{3}$.

There is widespread feeling among administrators, policy makers and senior managers, that improper project implementation, and delays in decision-making, have increased the capital costs of projects. This has put pressure on prices of final output, or led to increasing deficits when the prices are held down by administrative measures ${ }^{2}$ and hence indirectly to general inflation. The fact is that a rough measure of the degree of cost escalation is not available. Are the delays and cost escalation primarily due to bureaucratic styles of functioning? How far are the individual enterprises responsible? Are there genuine problems arising out of technical difficulties, inadequate experience, of learning by doing, additional costs of technological self-reliance, additional costs arising from price preference for domestic contractors and suppliers which cannot be set right by administrative reform alone?

Numerous models have been developed to control these overruns e.g., PERT/cost, PERT/time, PERT/performance. PERT/time has proved ineffective in controlling resources: time, cost, and performance ${ }^{5}$. Focusing these factors, companies started reconstructing PERT/time into PERT/cost and PERT/performance models. PERT/cost which is an extension of PERT/time and try to attempts to overcome the problems associated with the use of the most optimistic and most pessimistic time for estimating completion. As a result, PERT/cost is regarded as a cost accounting network model based on the work breakdown structure and capable of being subdivided down to the lowest elements, or work packages. The advantages of PERT/cost are that it:

- Contains all the features of PERT/time and

- Permits cost control at any WBS level

The aim for the development of PERT/cost was that project managers could identify critical schedule slippages and cost overruns in time to take corrective measures. Many attempts have been made to develop an effective PERT/schedule models, e.g., the accomplishment/cost procedure, (ACP). Block ${ }^{4}$ described ACP reports cost based on schedule accomplishment, rather than on the passage of time. To determine how an uncompleted task is progressing with respect to cost, ACP compares:

(a) cost/progress relationship budgeting with

(b) the cost/progress relationship expended for the task.

It utilizes data accumulated from periodic reports and from the same data base generates the following:

- The relationship between cost and scheduled performance

- The accounting relationships between cost and fiscal accounting requirements

- The prediction of corporate cash flow needs 
Unfortunately, the development of PERT/schedule techniques are still in its infancy. Although their applications have been identified, many companies feel locked in with their present method of control, whether it is PERT, CPM, or some other technique ${ }^{5}$.

\section{Literature Review}

Project Managers are increasingly facing complex challenges during the execution of engineering projects and it will be much more complex with the passage of time during the coming years. These challenges include high escalation factors for salaries and raw materials, increased energy prices, high union demands, increased pressure from stockholders, and the possibility of long-term high inflation accompanied by a mild recession as well as lack of borrowing power with financial tiers. These alarming factors were existed as before, but not to such a high degree that they are today ${ }^{5}$.

In the past, project managers have attempted to minimize the impact of these alarming factors by taking some corrective actions as massive cost-reduction programs. The results of these programs have been as early retirement, layoffs, and a reduction in manpower through attrition. As a result, jobs become vacant, project managers pressure line managers to accomplish the same amount of work with less resources, either by improving efficiency of project staff or by enhancing performance requirements to a higher position on the learning curve. Since project staff costs are more inflationary than the cost of equipment or facilities, project managers are funding more and more capital equipment projects to enhance productivity without increasing project staff ${ }^{5}$.

Unfortunately, project managers are somewhat limited in how far they can go to reduce manpower without running a high risk to corporate profitability. Capital equipment projects are not always the answer. Therefore, project managers have to look in details for the solutions to their problems.

Many project managers are not willing to accept change and are inflexible when it comes to adapting to different alarming factors. The project management approach requires a departure from the traditional business organizational form, which is basically vertical and which emphasizes a strong superior-subordinate relationship.

As shown in figure-1, normally companies are structured. There are always "class or prestige" gaps between various levels of management. There are also functional gaps between working units of the organization. If we superimpose the management gaps on top of the functional gaps, we find that companies are made up of small operational islands that refuse to communicate with one another for fear that giving up information may strengthen their opponents. The project manager's responsibility is to get these islands to communicate cross-functionally toward common goals and objectives ${ }^{5}$. 

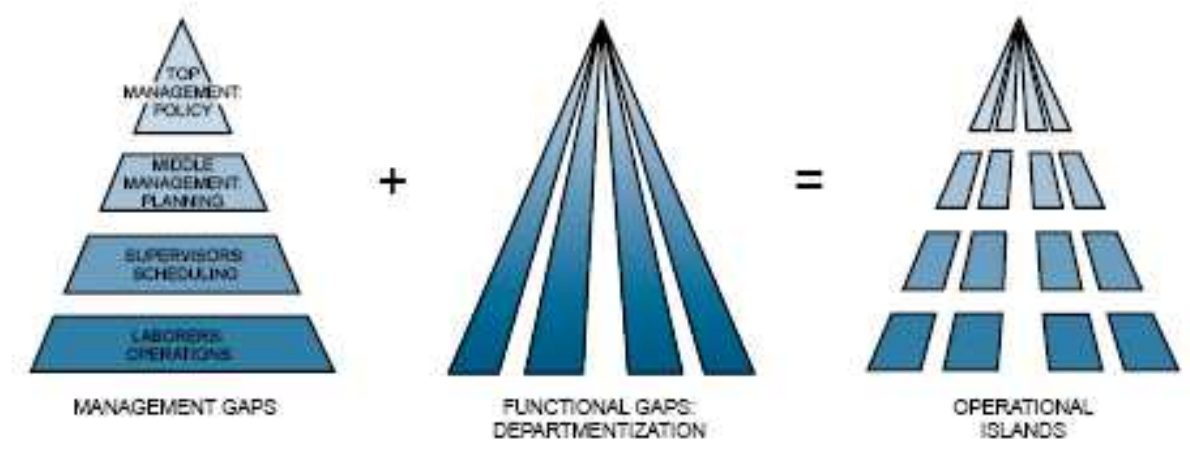

Figure-1 An Overview of Management and Functional Gaps ${ }^{5}$

Researchers have identified failures of projects in the 1980s as quantitative, mainly due to:

- Ineffective planning

- Ineffective scheduling

- Ineffective estimating

- Ineffective cost control

- Project objectives being "moving targets"

However during the 1990s, changed view of failure from being quantitatively oriented to qualitatively oriented and largely attributed to:

- Poor morale

- Poor motivation

- Poor human relations

- Poor productivity

- No employee commitment

- No functional commitment

- Delays in problem solving

- Too many unresolved policy issues

- Conflicting priorities between executives, line managers, and project Managers

Recently successful development and implementation of a project management methodology requires:

- Identification of the most common reasons for change in project management

- Identification of the ways to overcome the resistance to change

- Application of the principles of organizational change management to ensure that the desired project management environment will be created and sustained

Most organizational scholars and observers recognize that organizational culture has a powerful effect on the performance and long-term effectiveness of organizations. It was not until the beginning of the 1980s that organizational scholars began paying serious attention to the concept of culture (see, for example, references ${ }^{6,7,8}$ ). This is one of the 
few areas, in fact, in which organizational scholars led practicing project managers in identifying a crucial factor affecting organizational performance.

An organization's culture is reflected by what is valued, the dominant leadership styles, the language and symbols, the procedures and routines, and the definitions of success that makes an organization unique ${ }^{1}$. Cameron and Quinn ${ }^{1}$ have defined four different types of organizational culture. These are represented as adhocracy, clan, hierarchy, and market. They have suggested the different leadership styles or managerial styles pertaining to the respective organizational culture. When an organization is dominated by the hierarchy culture, the leadership style shown is that of organizing, controlling, monitoring, administering, coordinating, and maintaining efficiency. When an organization is dominated by the market culture, the managers are good at directing, producing results, negotiating, and motivating others. When the organization is dominated by the clan culture, the most effective leaders are parent figures, team builders, facilitators, nurturers, mentors, and supporters. Effective leaders in organizations dominated by the adhocracy culture tend to be entrepreneurial, visionary, innovative, creative, risk oriented, and focused on the future. Adhocracy leaders are rule breakers, for example, whereas hierarchy leaders are rule rein forcers. Clan leaders are warm and supportive, whereas market leaders are tough and demanding. Clan type organizational can have an affect in controlling project overruns as clan culture is the most effective and leaders are parent figures, team builders, facilitators, nurturers, mentors, and supporters.

In a study by Vidalis and Najaf ${ }^{9}$, for Florida Department of Transportation (FDOT) highway projects, there were complex and interrelated reasons why FDOT experiences cost and time overruns from delays in constructing transportation projects. Cost and time overruns in more than 700 FDOT projects overt two years (1999-2001). About 39\% of the delays were attributed from errors and omissions in plans and modification. Plans and modifications include changes in construction blueprints, changes in specifications, and changes in materials and quantities needed for the job after design plans were completed (FDOT 1997). These issues also included plans that were not in the contract, plans that required to be built different, adjustments in plans, and additions to plans.

In a study by Choudury that correlates time overrun in industrial construction projects in India, results of the study reveals that the total number of changes made during construction of an industrial project in India has a statistically significant effect on time overrun. The higher the number of change orders, the more is the actual construction time. This is not very surprising in context of Indian construction scenario. Generally, it takes a long time to process a change order due to tedious bureaucratic procedures. This is more visible in industrial construction, where most of the clients are governmental agencies or public sector companies.

A study by Nida Azhar ${ }^{10}$ for cost overrun factors in construction industry of Pakistan, major conclusions were: 
- The survey results indicated that the majority of cost overrun factors $(88 \%)$ lie in medium severity impact range. Attention should be paid to these factors as they cause considerable increase in the cost of the project initially estimated.

- Survey results indicate that both internal and external aspects of business setting contribute to cost overruns.

- Macro economical factors affect the cost of the construction project most severely.

- Among all factors leading to cost overruns, management related factors are those which can be controlled and prevented most easily as they are the inhouse factors.

- Business and regulatory environment is dysfunctional and need drastic changes, more scientifically proven methods, tools and techniques may be adopted instead of the orthodox practices

- Almost every project in the local industry faces cost overruns when executed. Minimum range of cost overrun in percentage of the estimated cost is at least $10 \%$.

- Medium sized firms are more prone to cost overruns in comparison with small and large firms, main reason for which being that they are in the transitional phase where they need to take more risk to get more business and establish them.

\section{Variance and Earned Value}

A variance is defined as any schedule, technical performance, or cost deviation from a specific plan ${ }^{5}$. Variances must be tracked and reported. They should be mitigated through corrective actions and not eliminated through a baseline change unless there is a good reason.

Variances are used by all levels of management to verify the budgeting system and the scheduling system. The budgeting and scheduling system variance must be compared because:

- The cost variance compares deviations only from the budget and does not provide a measure of comparison between work scheduled and work accomplished.

- The scheduling variance provides a comparison between planned and actual performance but does not include costs. Variances are used on both types of measurement.

In order to calculate variances, Archibald ${ }^{11}$ defines three basic variances for budgeting and actual costs for work scheduled and performed, as follows:

- Budgeted cost for work scheduled (BCWS) is the budgeted amount of cost for work scheduled to be accomplished plus the amount or level of effort or apportioned effort scheduled to be accomplished in a given time period.

- Budget cost for work performed (BCWP) is the budgeted amount of cost for completed work, plus budgeted for level of effort or apportioned effort activity completed within a given time period. This is sometimes referred to as "earned value." 
- Actual cost for work performed (ACWP) is the amount reported as actually expended in completing the work accomplished within a given time period.

- Cost variance (CV) can be calculated as:

$$
C V=B C W P \text { - ACWP }
$$

A negative variance indicates a cost-overrun condition.

- Schedule variance (SV) can be calculated as:

$$
\mathrm{SV}=\mathrm{BCWP}-\mathrm{BCWS}
$$

A negative variance indicates a behind-schedule condition.

Traditional project management techniques used by different project managers focus primarily on budget management, resource allocation, project planning and other administrative aspects to manage the projects, however the entire element of project management has been completely neglected. This element or aspect has to do with people, human elements of managing the projects, and are equally important in making a project successful.

To look into the aspect of human element for success engineering project, two research questions were required to be explored to answer the research questions. The research questions were:

1. Whether human consideration is a key to successful engineering project completion?

2. Whether project managers' strong human resource skills guarantee successful engineering projects?

\section{Methodology}

This research was quantitative in enquiry and was targeted at examining whether human element is a basic concentration for successful engineering projects. From the literature review, it is evident that whatever the causes of failure of projects, human element has an important consideration. To look into the success factor of human element in engineering project, a questionnaire was formulated based on the consideration of human element and it was either emailed or posted to engineering project managers, assistant project managers and functional managers with a request for an early return to the researchers. A total of 179 questionnaires were emailed or posted to various engineering projects personals. Out of 179 questionnaires, 137 questionnaires were received back duly filled resulting a $76 \%$ response rate. Responses were analyzed quantitatively using SPSS.

This study also considered and analyzed the effects of clan type project culture on successful engineering project. Details of some of the data collected are summarized in table-1 to table-3 as follows: 
Table 1: Details of Data Collection

\begin{tabular}{|l|c|c|}
\hline \multicolumn{1}{|c|}{ Industry / Project } & No. of Participants & Percentage \\
\hline Manufacturing Projects & 39 & 28.46 \\
\hline Road Construction & 24 & 17.55 \\
\hline R \& D Projects & 19 & 13.86 \\
\hline Buildings Projects & 27 & 19.73 \\
\hline Industrial Projects & 28 & 20.43 \\
\hline Total & 137 & 100 \\
\hline
\end{tabular}

In term of years of service, respondents' work experience in their respective projects is tabulated as follows:-

Table 2: Demographic Data

\begin{tabular}{|c|c|c|}
\hline No. of Years of Service & No. of Participants & Percentage \\
\hline $0-3$ & 64 & 46.71 \\
\hline $3-5$ & 28 & 20.43 \\
\hline $5-8$ & 26 & 18.97 \\
\hline $8-12$ & 19 & 13.89 \\
\hline Total & 137 & 100 \\
\hline
\end{tabular}

The respondents were asked to give their opinion either Yes or No about a number of questions and some of the questions are summarized as shown in table-3 
Table 3: Summary of Data Collected

\begin{tabular}{|l|c|c|}
\hline \multicolumn{1}{|c|}{ Questions } & $\begin{array}{c}\text { No. of } \\
\text { Respondents } \\
\text { responded } \\
\text { "Yes" }\end{array}$ & $\begin{array}{c}\text { No. of } \\
\text { Respondents } \\
\text { responded } \\
\text { "No" }\end{array}$ \\
\hline $\begin{array}{l}\text { Do you think the project manager's human } \\
\text { resource management knowledge is a key for } \\
\text { successful engineering project completion? }\end{array}$ & 123 & 14 \\
\hline $\begin{array}{l}\text { Does project manager's attitude and management } \\
\text { skill help in making the engineering project a } \\
\text { success? }\end{array}$ & 119 & 18 \\
\hline $\begin{array}{l}\text { Do you think project team member's commitment is } \\
\text { a necessary ingredient for successful engineering } \\
\text { project completion? }\end{array}$ & 137 & 0 \\
\hline $\begin{array}{l}\text { Does any project team member non-commitment } \\
\text { can affect successful completion of engineering } \\
\text { project? }\end{array}$ & 131 & 6 \\
\hline $\begin{array}{l}\text { Do you think project manager's close relations with } \\
\text { his/her project team members contribute towards } \\
\text { successful engineering project? }\end{array}$ & 134 & 3 \\
\hline $\begin{array}{l}\text { Does project management team;s loyalty towards } \\
\text { hid/her project can cause projects overrun in terms } \\
\text { of time and cost? }\end{array}$ & 132 & \\
\hline $\begin{array}{l}\text { Do you think project manager's promoting a clan } \\
\text { type family) project culture can contributes } \\
\text { towards successful engineering project } \\
\text { completion? }\end{array}$ & 131 & \\
\hline
\end{tabular}

\section{Data Analysis}

It is evident from the results of the data collected that more humane a project manager/ assistant project manager/ functional manager is, and he/she has close relations with their project team members like a clan type organizational culture, and all team members are committed to their work and project team is loyal to their projects, the more chances are for the engineering project to be completed on time and within budget as follows:-
a) Project completed on time
b) Project completed within budget
c) Project completed within scope 

d) Project achieved all desired objects
e) Project met all stakeholders satisfaction

\section{Proposed Model for Successful Engineering Projects}

From the results of this research, a model is developed for the success of engineering projects as shown in figure number 2.

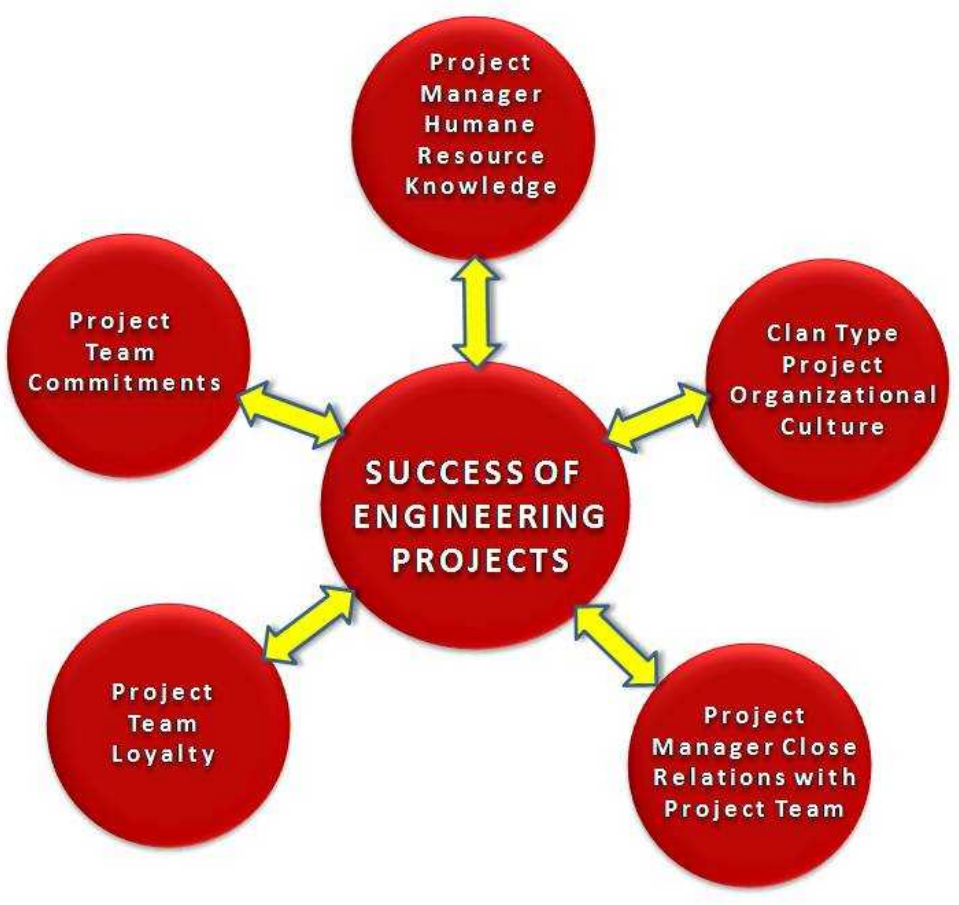

Figure No. 2 Model for the Success of Engineering Projects.

\section{Discussion}

It is eminent from the results of this research that mere technical competence is not enough for project managers/assistant project manager/ functional managers to make a engineering project successful since large number of projects fail in spite of costly technology and project techniques. It is well known fact that there are no standards available to analyze and integrate human aspects necessary to handle pressure and work stresses on project team members, and to develop associations among team members, as well as to motivate project team 
members. This study has highlighted the fact that human element is vital for the success of engineering projects.

Another significant aspect for successful engineering projects is the way project managers/assistant project managers/ functional managers lead their teams. As Alexander said "I should prefer an army of stags led by a lion, to an army of lions led by a stag". This study has provided an insight into the causes of failure for engineering projects and strengthen the fact that engineering projects can be a success if project managers/assistant project managers/ functional managers apply effective leadership/management skills with project team, promote clan type project culture, develop close relationship with project team, improve project team commitments and loyalty with the project, as it is also depicted in the model developed shown in figure-2 for the success of engineering projects.

\section{Recommendations and Conclusions}

It is recognized fact that engineering projects are the most heavily budgeted and consume a large portion of a nation's economy in terms of public sector projects and a large amount organizational budget in terms of private sector projects. If engineering projects are overrun, project is considered to be a failure in terms of time or cost since budget utilized in a failure engineering project is blocked with no output as planned.

It is an absolutely necessary for engineering projects to be completed on time and within budget. An important element that is normally neglected during the execution of engineering projects is the humane consideration. Human resource management/leadership skills that is considered to be a key for the successful completion of any project is also vital for effective completion of engineering projects. It is evident from the results of this research that if engineering project team is not committed, loyal to the project and project management team is lacking management/leadership skills, engineering project may end up in a failure. It is a necessary requirement for a successful engineering project that project team is committed, loyal to the project, have a close relationship like a clan type organizational culture as well as project management team possess management/leadership skills as it is depicted in the proposed model for successful completion of engineering projects shown in figure-2.

\section{Acknowledgement}

The author would like to acknowledge the support of National University of Science \& Technology and Higher Education Commission of Pakistan in the funding of this research. 


\section{Bibliography}

1. Cameron, K. S. and Quinn, R. E. Diagnosing and changing organisational culture, 1999 (AddisonWesley Longman, Reading, Massachusetts).

2. Steen Lichtenberg, How to avoid overruns and delays successfully. ICEC Internet Journal, Oct. 2005

3. Rangarajan, C. (1982), " Industrial Growth: Another Look", EPW, Annual No. Volume XVII, Nos. 14, 15 and 16

4. Ellery B. Block, "Accomplishment/Cost: Better Project Control," Harvard Business Review, May-June 1971, pp. 110-124.

5. Harold Kerzner, (2010). Project Management, A system approach to planning, scheduling and control. John Wiley \& Sons, New Jersey. ISBN: 978-0-471-26557-3

6. Deal, T. E. and Kennedy, A. A. Corporate cultures: the rights and rituals of corporate life, 1982 (Addison- Wesley, Reading, Massachusetts).

7. Ouchi, W. G. Theory Z: how American business can Meet the Japanese challenge, 1981 (AddisonWesley, Reading, Massachusetts).

8. Peters, T. J. and Waterman, Jr, R. H. In search of excellence: lessons from America's best run companies, 1982 (Harper \& Row, New York).

9. S. M. Vidalis A, F.T. Najafi B. Cost and time overruns in highway construction. $4^{\text {th }}$ Transportation Specialty Conference of the Canadian Society for Civil Engineering Montréal, Québec, Canada 5-8 juin 2002 / June 5-8, 2002

10. Nida Azhar, Cost Overrun Factors In Construction Industry of Pakistan First International Conference on Construction In Developing Countries (ICCIDC-I) "Advancing and Integrating Construction Education, Research \& Practice" August 4-5, 2008, Karachi,, Pakistan

11. Russell D. Archibald (2003), Managing high-technology programs and projects. John Wiley \& Sons, New Jersey. ISBN: 978-0-471-26557-3 